\title{
Activity-Dependent Regulation of Potassium Currents in an Identified Neuron of the Stomatogastric Ganglion of the Crab Cancer borealis
}

\author{
Jorge Golowasch, L. F. Abbott, and Eve Marder \\ Volen Center and Department of Biology, Brandeis University, Waltham, Massachusetts 02454
}

Identified neurons of the stomatogastric ganglion of the crab Cancer borealis were voltage-clamped, and the current densities of three $\mathrm{K}^{+}$currents were measured. The current densities of each of the three $\mathrm{K}^{+}$currents varied twofold to fivefold in inferior cardiac (IC) neurons from different animals. Conventionally, this degree of variability has been attributed to experimental artifacts. Instead, we suggest that it reflects a natural variability that may be related to an underlying process of plasticity. First, we found that there is no fixed ratio among the three $\mathrm{K}^{+}$ currents. Second, we found that several hours of stimulation with depolarizing current pulses $(0.5 \mathrm{sec}$ duration at $1 \mathrm{~Hz})$ altered the current density of the $\mathrm{Ca}^{2+}$-dependent outward current, $I_{\mathrm{K}(\mathrm{Ca})}$, and the transient outward current, $I_{\mathrm{A}}$. This stimulation paradigm mimics the normal pattern of activity for these

The intrinsic electrical properties of neurons depend on the ionic currents they express. Measurements of the densities of ionic currents frequently exhibit high levels of variability from cell to cell (Liu et al., 1998). This variability has traditionally been attributed to recording artifacts. However, studies of multiconductance-based model neurons show that very similar intrinsic patterns of activity can be produced by neurons with different conductance densities (Liu et al., 1998; M. S. Goldman, J. Golowasch, E. Marder, and L. F. Abbott, unpublished observations). Moreover, recent experimental and theoretical work argues that neuronal electrical activity can regulate and modify ionic conductances (Franklin et al., 1992; Abbott and LeMasson, 1993; LeMasson et al., 1993; Siegel et al., 1994; Turrigiano et al., 1994, 1995; Hong and Lnenicka, 1995, 1997; Liu et al., 1998; Desai et al., 1999; Golowasch et al., 1999; Stemmler and Koch, 1999). These results suggest that cells do not maintain fixed conductance densities, but rather regulate their conductances to maintain a characteristic pattern of activity, and that they do so in an activity-dependent manner.

The regulation of ionic currents by electrical activity has been most extensively studied in development or in cell culture (Turrigiano et al., 1994, 1995; Desai et al., 1999). In this paper, we study different identified neurons from the crustacean stomatogastric ganglion (STG) to ask whether altered patterns of activity can produce significant changes in conductance densities in adult neurons over relatively short time periods.

\footnotetext{
Received June 4, 1999; revised July 21, 1999; accepted July 27, 1999.

This work was supported by National Institutes of Mental Health Grant $\mathrm{MH}$ 46742 and the W. M. Keck Foundation.

Correspondence should be addressed to Dr. Jorge Golowasch, Volen Center Mail Stop 013, Brandeis University, 415 South Street, Waltham, MA 02454.

Copyright (C) 1999 Society for Neuroscience $\quad 0270-6474 / 99 / 190001-\bullet \$ 05.00 / 0$
}

neurons. The effect of stimulation on the $I_{\mathrm{A}}$ current density was eliminated when $\mathrm{Ca}^{2+}$ influx was blocked by extracellular $\mathrm{Cd}^{2+}$. In contrast, the $\mathrm{K}^{+}$current densities of the lateral pyloric (LP) neuron were unaffected by the same pattern of stimulation, and the currents expressed by both the IC and the LP neurons were insensitive to hyperpolarizing pulses at the same frequency. We conclude that the conductance densities expressed by neurons may vary continually depending on the recent history of electrical activity in the preparation, and that intracellular $\mathrm{Ca}^{2+}$ may play a role in the processes by which activity influences the regulation of current densities in neurons.

Key words: potassium currents; transient outward current; delayed rectifier; $\mathrm{Ca}^{2+}$-dependent $\mathrm{K}^{+}$current; calcium signaling; crustacean; voltage clamp

\section{MATERIALS AND METHODS}

STGs of adult Cancer borealis were dissected, pinned on a Sylgard-lined Petri dish, and superfused with normal saline (in mM: $440 \mathrm{NaCl}, 11 \mathrm{KCl}$, $26 \mathrm{MgCl}_{2}, 13 \mathrm{CaCl}_{2}, 12$ Trizma base, and 5 maleic acid, $\mathrm{pH}$ 7.4-7.5). The STG was desheathed, and cells were identified (Hooper et al., 1986). Neurons were impaled with two microelectrodes filled with $0.6 \mathrm{M} \mathrm{K}_{2} \mathrm{SO}_{4}$ plus $20 \mathrm{~mm} \mathrm{KCl}(15-25 \mathrm{M} \Omega$ resistance) or with $3 \mathrm{M} \mathrm{KCl} \mathrm{(10-15} \mathrm{M} \Omega$ resistance). Results for the two electrode filling electrolytes showed no difference and have thus been combined. Ionic currents were measured in two-electrode voltage clamp (TEVC) using an Axoclamp $2 \mathrm{~A}$ amplifier, Digidata 1200A interface, and the pClamp software (Axon Instruments, Foster City, CA) in either normal saline plus $10 \mu \mathrm{M}$ picrotoxin (PTX; Sigma, St. Louis, MO) to block glutamatergic synapses or in PTX plus $0.1 \mu \mathrm{M}$ tetrodotoxin (TTX; Sigma) to additionally block action potential generation. The presence of PTX and/or TTX in the bath made no difference to the ionic current measurements (data not shown). In the absence of TTX, only some extra current noise from poorly clamped action potentials riding on top of the outward currents is observed. Current-clamp experiments were performed with two electrodes (2ECC) in normal saline plus PTX throughout. Action potential conduction along the input stomatogastric nerve was blocked by placing a vaseline well filled with isotonic sucrose (750 mM sucrose plus $1 \mu \mathrm{M}$ TTX) around it.

We chose to study the three $\mathrm{K}^{+}$outward currents in STG neurons.

This article is published in The Journal of Neuroscience, Rapid Communications Section, which publishes brief, peerreviewed papers online, not in print. Rapid Communications are posted online approximately one month earlier than they would appear if printed. They are listed in the Table of Contents of the next open issue of JNeurosci. Cite this article as: JNeurosci, 1999, 19:RC33 (1-5). The publication date is the date of posting online at www.jneurosci.org.

http://www.jneurosci.org/cgi/content/full/3496 


A

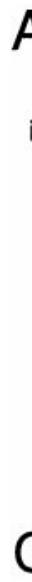
sured at $V_{\mathrm{m}}=+20 \mathrm{mV}$, and the conductance was calculated with an estimated $E_{\mathrm{REV}}$ value of -80 $\mathrm{mV}$. The ratios between maximum and minimum values for each conductance are shown above each data set. Notice that the ratios are between 2.1 and 4.4 , except for $g_{\text {leak }}$, which shows a much higher variability. The total conductance density, $g_{\text {total }}$, is the sum of the conductance densities of all three $\mathrm{K}^{+}$ currents. Mean values $( \pm$ SD) are: membrane capacitance, $0.48 \pm 0.09 \mathrm{nF}$; resting potential, $-50.2 \pm 6.7 \mathrm{mV} ; g_{\mathrm{Kd}}=0.35 \pm 0.13 \mu \mathrm{S} / \mathrm{nF} ; g_{\mathrm{K}(\mathrm{Ca})}=$ $2.68 \pm 0.68 \mu \mathrm{S} / \mathrm{nF} ; g_{\mathrm{A}}=0.74 \pm 0.18 \mu \mathrm{S} / \mathrm{nF} ; g_{\text {leak }}=$ $0.40 \pm 0.24 \mu \mathrm{S} / \mathrm{nF}$; and $g_{\text {total }}=3.76 \pm 0.76 \mu \mathrm{S} / \mathrm{nF} . D$, Coefficients of variation ( $\mathrm{SD} /$ mean) of each of the data sets shown in $C$.

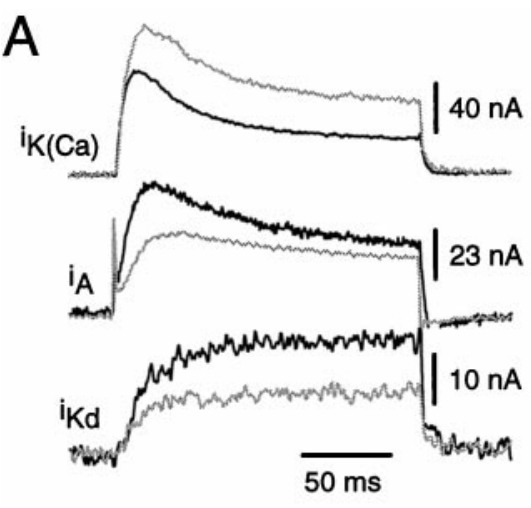

B

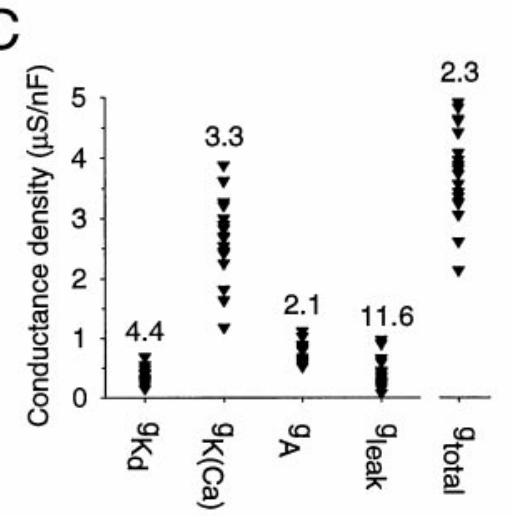

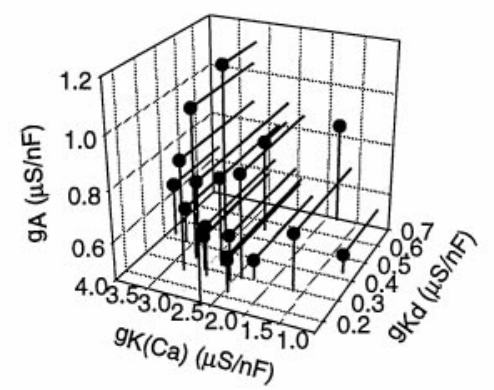

D

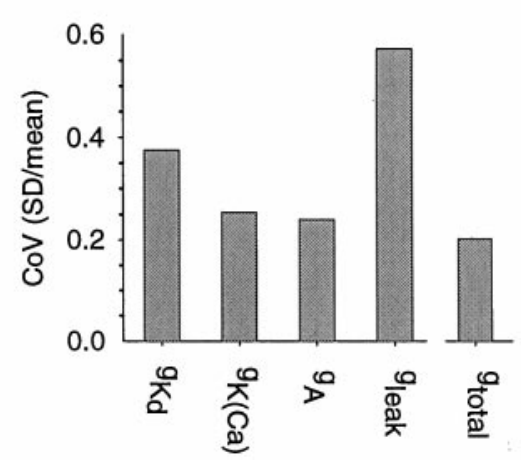

They are easily measured, adequately clamped with somatic electrodes, and relatively easy to separate by manipulations of the membrane potential and pharmacological agents. All three $\mathrm{K}^{+}$currents activate at membrane potentials more depolarized than $-40 \mathrm{mV}$. The delayed rectifier current $\left(I_{\mathrm{Kd}}\right)$ was measured in TEVC from a holding potential $V_{\mathrm{h}}$ $=-40 \mathrm{mV}$ in the presence of $500 \mu \mathrm{M} \mathrm{Cd}^{2+}$. The $\mathrm{Ca}^{2+}$-activated $\mathrm{K}^{+}$ current $\left(I_{\mathrm{K}(\mathrm{Ca})}\right)$ was measured as the current difference between the current measured in normal saline and the current remaining in the presence of $500 \mu \mathrm{M} \mathrm{Cd}^{2+}$ from $V_{\mathrm{h}}=-40 \mathrm{mV}$. Finally, $I_{\mathrm{A}}$ was measured either in normal saline or in the presence of $500 \mu \mathrm{M} \mathrm{Cd}^{2+}$ as the difference in currents evoked from $V_{\mathrm{h}}=-80 \mathrm{mV}$ minus $V_{\mathrm{h}}=-40 \mathrm{mV}$. The peak currents were measured at $+20 \mathrm{mV}$, and chord conductances were calculated from the equation $g=I /\left(V_{\mathrm{m}}-E_{\mathrm{REV}}\right)$ with an estimated $E_{\mathrm{REV}}$ value of $-80 \mathrm{mV}$ for all three outward $\mathrm{K}^{+}$currents, and where $V_{\mathrm{m}}$ is the membrane potential during a voltage-clamp pulse. The leak current was measured from fits with a linear equation, $I_{\text {leak }}=g_{\text {leak }} \cdot\left(V_{\mathrm{m}}-E_{\mathrm{REV}}\right)$, and $V_{\mathrm{m}}=-40,-50,-60$, and $-70 \mathrm{mV}$. The membrane capacitance $\left(C_{\mathrm{m}}\right)$ was measured by integrating the current over time for short voltage steps to membrane potentials where no active currents are elicited $(-80$ to $-40 \mathrm{mV}$ ). All currents are expressed as current densities normalized to the measured cell capacitance. The stimulation protocol in $2 \mathrm{ECC}$ consisted of $500 \mathrm{msec}$ depolarizing or hyperpolarizing current pulses at $1 \mathrm{~Hz}$. The current injection level was adjusted to depolarize the cells to a baseline $V_{\mathrm{m}} \sim-25 \mathrm{mV}$ or to hyperpolarize them to $V_{\mathrm{m}} \sim-90 \mathrm{mV}$, respectively.

\section{RESULTS}

All STG neurons studied express three outward $\mathrm{K}^{+}$currents, a delayed rectifier current $\left(I_{\mathrm{Kd}}\right)$, a $\mathrm{Ca}^{2+}$-activated current $\left(I_{\mathrm{K}(\mathrm{Ca})}\right)$, and a transient A-type current $\left(I_{\mathrm{A}}\right)$ (Graubard and Hartline, 1991; Golowasch and Marder, 1992; Tierney and Harris-Warrick, 1992; Harris-Warrick et al., 1995; Kloppenburg et al., 1999). We measured the conductance densities of these three outward $\mathrm{K}^{+}$ currents in the inferior cardiac (IC) neuron of 18 preparations (Fig. 1). Figure $1 A$ shows current traces from two different neurons, shown in black and gray, respectively. The amplitude of $I_{\mathrm{K}(\mathrm{Ca})}$ was larger in the neuron shown in gray, but the amplitudes of $I_{\mathrm{A}}$ and $I_{\mathrm{Kd}}$ were larger in the neuron shown in black. This suggests that different neurons do not maintain a fixed ratio of these three $\mathrm{K}^{+}$currents, but that they can vary in amplitude independently.

Figure $1 B$ is a three-dimensional plot in which the conductance densities of the three currents in all 18 IC neurons are displayed. If the three currents were proportionally scaled, the points would line up along a straight line going from the lower right front to the upper left back corner of the graph. Although the points show a tendency to fall in a plane parallel to such a line, the values show a great degree of dispersion, showing that proportional scaling is not occurring. Instead, the broad distribution observed indicates a lack of correlation between the conductance densities of these three currents (three-dimensional regression analyses with a plane: $r=0.406 ; p=0.26$; with a hyperbola: $r=0.527 ; p=0.34$ ).

Figure $1 C$ shows the peak conductance densities for each of the three $\mathrm{K}^{+}$currents, for the sum of the $\mathrm{K}^{+}$currents $\left(g_{\text {total }}\right)$, and the conductance density for the leak current. The ratios between the maximum and the minimum measured conductance densities for each ionic current are shown above each set of data. The conductance densities of the $\mathrm{K}^{+}$currents range between 2.1 and 4.4 over the 18 neurons studied, and the leak conductances vary even more. Interestingly, the sum of the three $\mathrm{K}^{+}$currents varies less than either those of the delayed rectifier and $\mathrm{Ca}^{2+}$-activated $\mathrm{K}^{+}$ currents (Fig. 1C). Figure $1 D$ shows the coefficient of variation ( $\mathrm{SD} /$ mean) for the three voltage-dependent and the leak currents. By this measure, the total of the $\mathrm{K}^{+}$conductance densities is marginally less variable than any of the individual currents.

To test whether patterned activity imposed experimentally could alter the conductance density of one or more of the $\mathrm{K}^{+}$ currents, we stimulated the IC neuron rhythmically $(1 \mathrm{~Hz}, 50 \%$ duty cycle) for several hours under current clamp. Every $60 \mathrm{~min}$, the recording configuration was switched to voltage clamp, and the ionic currents were measured. Figure $2 A$ illustrates the effects 

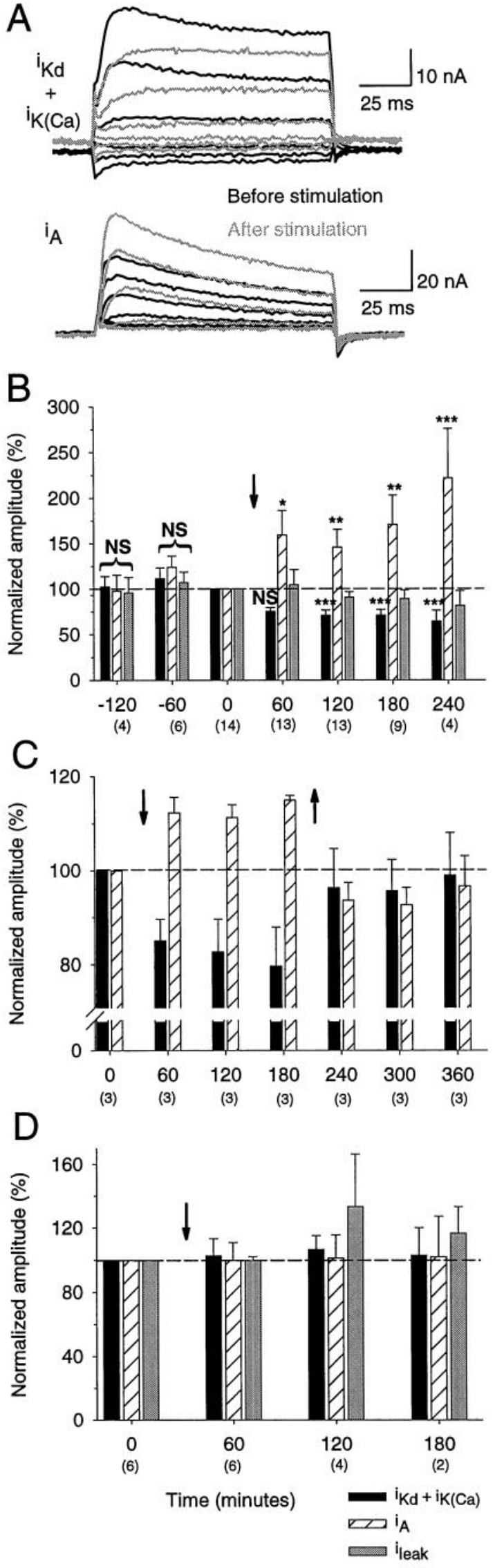

of this stimulation. The dark traces correspond to the current elicited before stimulation and the lighter traces to those elicited after $240 \mathrm{~min}$ of patterned depolarizing current injection. The top traces correspond to the sum of $I_{\mathrm{Kd}}$ and $I_{\mathrm{K}(\mathrm{Ca})}$, and the bottom traces correspond to $I_{\mathrm{A}}$. In these experiments, $I_{\mathrm{Kd}}$ and $I_{\mathrm{K}(\mathrm{Ca})}$ cannot effectively be separated because separating these currents involves applying, and then washing $\mathrm{Cd}^{2+}$ (see Materials and Methods) during every ionic current measurement (e.g., every 60 min). Therefore, the sum of these two currents is reported throughout the remainder of this paper. Notice that $I_{\mathrm{Kd}}$ plus $I_{\mathrm{K}(\mathrm{Ca})}$ decreased, and $I_{\mathrm{A}}$ markedly increased in amplitude as a consequence of the stimulation, whereas $I_{\text {total }}$ decreases because of the decrease of the dominant $I_{\mathrm{Kd}}$ plus $I_{\mathrm{K}(\mathrm{Ca})}$.

Figure $2 B$ summarizes the effect of patterned depolarizing stimulation on 14 IC neurons. Before the beginning of stimulation (time, $-120-0 \mathrm{~min}$ ) the measured current densities were stable. Within the first hour of stimulation (which begins at the arrow), however, $I_{\mathrm{Kd}}$ plus $I_{\mathrm{K}(\mathrm{Ca})}$ began to decrease until it reached a minimum value of $\sim 70 \%$ of control after $\sim 2 \mathrm{hr}$, whereas $I_{\mathrm{A}}$ increased its amplitude with a similar time course to reach a maximum value $\sim 250 \%$ of control. These trends are statistically significant for $I_{\mathrm{Kd}}$ plus $I_{\mathrm{K}(\mathrm{Ca})}$ and $I_{\mathrm{A}}$. In contrast, the leak current showed no statistically significant variation in amplitude during the same period of time. The change in $I_{\mathrm{Kd}}$ plus $I_{\mathrm{K}(\mathrm{Ca})}$ is likely to be mainly a result of $I_{\mathrm{K}(\mathrm{Ca})}$, because the largest $I_{\mathrm{Kd}}$ measured in an IC neuron is of lower amplitude than the activity-induced current change.

Figure $2 C$ shows a similar result for three IC neurons that were recorded long enough to demonstrate that this effect fully reverses over time after the stimulation was terminated. Notice that the phenomenon reverses with approximately the same time course as the onset of the current changes during stimulation. Figure $2 D$ shows the effect of stimulating six IC neurons in the presence of $\mathrm{Cd}^{2+}$ to block the $\mathrm{Ca}^{2+}$ current expressed by these cells (Golowasch and Marder, 1992). Here we observe that the effect on $I_{\mathrm{A}}$ is completely abolished. The effect on $I_{\mathrm{K}(\mathrm{Ca})}$ is occluded by the fact that $I_{\mathrm{K}(\mathrm{Ca})}$ activation depends on $\mathrm{Ca}^{2+}$ entering the cell through $\mathrm{Ca}^{2+}$ channels, but no effect on $I_{\mathrm{Kd}}$ (the current remaining in the presence of $\mathrm{Cd}^{2+}$ ) can be observed

\section{$\leftarrow$}

Figure 2. Effect of patterned stimulation of the IC neuron. The peak current measured at $+20 \mathrm{mV}$ every 60 min was normalized to the peak current level at time 0 , i.e., immediately before the beginning of stimulation (downward arrow). Negative time indicates time before stimulation begins. Dashed lines indicate control values (i.e., 100\%). Numbers of measurements are indicated in parentheses under the time axes below the time label; the variability in these numbers is caused by the fact that different preparations survived different amounts of time and that in some cases stimulation was begun immediately after impalement. Values in $B-D$ are mean \pm SEM. $A$, Ionic current raw traces before (black traces) and after $4 \mathrm{hr}$ of stimulation (gray traces). $I_{\mathrm{Kd}}$ and $I_{\mathrm{K}(\mathrm{Ca})}$ are measured together from a $V_{\mathrm{h}}=-40 \mathrm{mV}$, and $I_{\mathrm{A}}$ is measured separately from a $V_{\mathrm{h}}=$ $-80 \mathrm{mV}$. $B$, The neurons were stimulated for as long as they survived. Before stimulation begins, current amplitudes are not statistically significantly different from control. Black bars correspond to $I_{\mathrm{K}(\mathrm{Ca})}+I_{\mathrm{Kd}}$, hatched bars to $I_{\mathrm{A}}$, and gray bars to $I_{\text {leak }}$. Statistical significance of the changes is shown above the bars for the other currents: $N S$, not statistically significant; ${ }^{*} p<0.05 ; *{ }^{*} p<0.01 ; * * * p<0.001$; ANOVA. $C$, Three neurons were stimulated for $3 \mathrm{hr}$ (between arrows) and finally held for 3 hr without stimulation to observe the recovery of the maximum current amplitudes. $I_{\text {leak }}$ is omitted for clarity because no statistically significant changes were observed. $D$, Same protocol as in $B$ but in the presence of $200 \mu \mathrm{M} \mathrm{Cd}^{2+}$ to block $\mathrm{Ca}^{2+}$ entry to the cells via $\mathrm{Ca}^{2+}$ channels (Golowasch and Marder, 1992). 

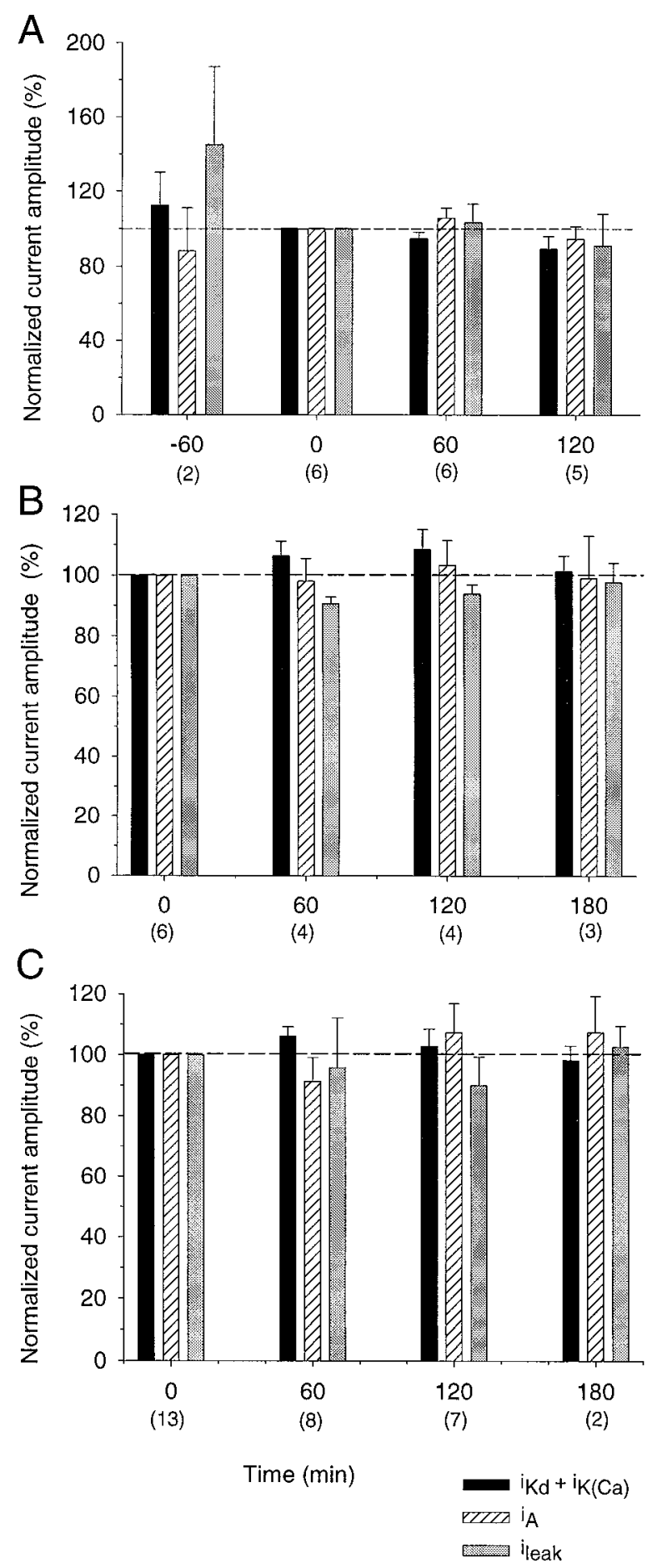

Figure 3. Effect of other stimulation paradigms and cell types. The temporal aspect of the stimulation protocol was identical to that used in Figure 2, but the polarity of the injected current was varied. Peak currents normalized to the peak current level at time 0 , immediately before the beginning of stimulation. Dashed lines indicate control values (100\%). Numbers of measurements are indicated in parentheses under the time axes below the time label. Values are mean \pm SEM. $A$, Stimulation of the LP neuron with depolarizing current. No effect of stimulation is observed. $B$, Effect of hyperpolarizing stimulation of the IC neuron, and of the LP neuron $(C)$. No effect was observed with hyperpolarizing current in either $B$ or $C$. under these conditions. These results indicate that the conductance density changes observed in response to the imposed activity pattern in IC depend on $\mathrm{Ca}^{2+}$ influx into the cell.

Figure $3 A$ shows that the same stimulus paradigm that alters the conductance densities measured in the IC neuron failed to elicit equivalent changes in another cell type in the STG, the lateral pyloric (LP) neuron. Figure $3, B$ and $C$, shows that neither the IC nor the LP neuron are affected by hyperpolarizing current stimulation. Taken together, this indicates that identified neurons in the STG respond differentially to specific patterns of activity and the polarity of the stimulus.

\section{DISCUSSION}

Ion channel proteins turn over rapidly relative to the lifetime of neurons, so ion channels must continually be replaced. Control of this process requires that the number, open conductance, and distribution of ion channels be regulated by feedback mechanisms related to the firing properties of the neuron (LeMasson et al., 1993; Liu et al., 1998; Stemmler and Koch, 1999). One of the salient observations of this paper and our previous work (Liu et al., 1998) is that there is considerable variation in conductance densities for different currents when individual neurons of the same class are compared (Fig. 1). Modeling work indicates that such a high degree of variability is consistent with a relatively constant pattern of activity (Liu et al., 1998; M.S. Goldman, J. Golowasch, E. Marder, and L.F. Abbott, unpublished data). The type of neuronal plasticity we report in this paper may act as a driving force for this variability by linking the conductances of a neuron to its recent history of activity.

Under physiological conditions, neurons of the STG are rhythmically active. The pattern of activity is influenced by sensory and modulatory inputs that can alter the ongoing motor pattern for either short or long periods of time. The activity-dependent changes in conductances reported here suggest that the conductance densities expressed by each neuron will depend on its history, with an "integration time constant" of several hours. Variability in measured conductances may thus reflect the variability in the activity of the STG before the recording. Interestingly, the changes produced, in the experiments reported here, by "natural" imposed patterns of depolarization fall within the range of variability observed among different preparations (Fig. 1).

Our data demonstrate that even 2 or $3 \mathrm{hr}$ of stimulation can significantly alter the currents that are measured in single IC neurons (Fig. 2). It is interesting that another neuronal type, the LP neuron, did not respond to the same pattern of depolarization. Each cell type may have a different sensitivity to activity so that stimulation with different frequencies or durations, or for much longer time periods (Desai et al., 1999), may be needed to elicit measurable changes in conductances in some neurons. This is consistent with a growing body of literature that argues that a variety of cellular processes may be sensitive to different temporal patterns of activity (Fields et al., 1990; Turrigiano et al., 1994; Itoh et al., 1995, 1997; Stevens et al., 1998). In our experiments, blocking the influx of $\mathrm{Ca}^{2+}$ into the cells abolished the effects of stimulation (Fig. 2C). Further support for the plasticity of conductances in the STG is provided by recent experiments that show that removal of modulatory inputs is first followed by loss of rhythmicity in the STG motor circuits followed by resumption of activity one to several days later (Thoby-Brisson and Simmers, 1998; Golowasch et al., 1999), presumably as the neurons that make up these circuits respond to changes in their activity levels and loss of modulatory inputs. 
Because the intrinsic properties of neurons depend on the number and type of all of their ionic currents, the variability and fluctuations reported here have several important consequences. One possibility is that changes in current densities alter the firing properties of neurons to compensate for other changes (Desai et al., 1999). Alternatively, it is possible that neurons with many different current types maintain relatively constant intrinsic electrical properties, although each current density can individually be quite variable (Liu et al., 1998; M. S. Goldman, J. Golowasch, E. Marder, and L.F. Abbott, unpublished data).

\section{REFERENCES}

Abbott LF, LeMasson G (1993) Analysis of neuron models with dynamically regulated conductances in model neurons. Neural Comput 5:823-842.

Desai NS, Rutherford LC, Turrigiano GG (1999) Plasticity in the intrinsic excitability of cortical pyramidal neurons. Nat Neurosci 2:515-520.

Fields RD, Neale EA, Nelson PG (1990) Effects of patterned electrical activity on neurite outgrowth from mouse sensory neurons. J Neurosci 10:2950-2964.

Franklin JL, Fickbohm DJ, Willard AL (1992) Long-term regulation of neuronal calcium currents by prolonged changes of membrane potential. J Neurosci 12:1726-1735.

Golowasch J, Marder E (1992) Ionic currents of the lateral pyloric neuron of the stomatogastric ganglion of the crab. J Neurophysiol 67:318-331.

Golowasch J, Casey M, Abbott LF, Marder E (1999) Network stability from activity-dependent regulation of neuronal conductances. Neural Comput 11:1079-1096.

Graubard K, Hartline DK (1991) Voltage clamp analysis of intact stomatogastric neurons. Brain Res 557:241-254.

Harris-Warrick RM, Coniglio LM, Barazangi N, Guckenheimer J, Gueron S (1995) Dopamine modulation of transient potassium current evokes phase shifts in a central pattern generator network. J Neurosci 15:342-358.

Hong SJ, Lnenicka GA (1995) Activity-dependent reduction in voltagedependent calcium current in a crayfish motoneuron. J Neurosci 15:3539-3547.

Hong SJ, Lnenicka GA (1997) Characterization of a P-type calcium current in a crayfish motoneuron and its selective modulation by impulse activity. J Neurophysiol 77:76-85.

Hooper SL, O’Neil MB, Wagner RJ, Ewer J, Golowasch J, Marder E (1986) The innervation of the pyloric region of the crab, Cancer borealis: homologous muscles in decapod species are differently innervated. J Comp Physiol [A] 159:227-240.

Itoh K, Ozaki M, Stevens B, Fields RD (1997) Activity-dependent regulation of $\mathrm{N}$-cadherin in DRG neurons: differential regulation of $\mathrm{N}$-cadherin, NCAM, and L1 by distinct patterns of action potentials. J Neurobiol 33:735-748.

Itoh KB, Stevens B, Schachner M, Fields RD (1995) Regulated expression of the neural cell adhesion molecule L1 by specific patterns of neural impulses. Science 270:1369-1372.

Kloppenburg P, Levini RM, Harris-Warrick RM (1999) Dopamine modulates two potassium currents and inhibits the intrinsic firing properties of an identified motor neuron in a central pattern generator network. J Neurophysiol 81:29-38.

LeMasson G, Marder E, Abbott LF (1993) Activity-dependent regulation of conductances in model neurons. Science 259:1915-1917.

Liu Z, Golowasch J, Marder E, Abbott LF (1998) A model neuron with activity-dependent conductances regulated by multiple calcium sensors. J Neurosci 18:2309-2320.

Siegel M, Marder E, Abbott LF (1994) Activity-dependent current distributions in model neurons. Proc Natl Acad Sci USA 91:11308-11312.

Stemmler M, Koch C (1999) How voltage-dependent conductances can adapt to maximize the information encoded by neuronal firing rate. Nat Neurosci 2:521-527.

Stevens B, Tanner S, Fields RD (1998) Control of myelination by specific patterns of neural impulses. J Neurosci 18:9303-9311.

Thoby-Brisson M, Simmers J (1998) Neuromodulatory inputs maintain expression of a lobster motor pattern-generating network in a modulation-dependent state: evidence from long-term decentralization in vitro. J Neurosci 18:2212-2225.

Tierney AJ, Harris-Warrick RM (1992) Physiological role of the transient potassium current in the pyloric circuit of the lobster stomatogastric ganglion. J Neurophysiol 67:599-609.

Turrigiano G, Abbott LF, Marder E (1994) Activity-dependent changes in the intrinsic properties of cultured neurons. Science 264:974-977.

Turrigiano GG, LeMasson G, Marder E (1995) Selective regulation of current densities underlies spontaneous changes in the activity of cultured neurons. J Neurosci 15:3640-3652. 